MARKETING - SAMENWERKING - ONDERZOEK

\title{
De rol van vertrouwen bij het opbouwen van lange-termijn- relaties in de dienstensector
}

\author{
Drs. I. Geyskens en Prof. Dr. Ir. J.E.B.M. Steenkamp
}

\section{Inleiding}

Relatiemarketing tekent zich af als een belangrijke nieuwe trend binnen markelingtheorie en -praktijk, en heeft de wijze veranderd warop ondernemingen met klanten omgaan. Meer en meer ondernemingen trachten duurzame competitieve voordelen te realiseren via het opbouwen van lange-termijnrelaties met hun klanten. Waar bij een transactiegerichte marketingbenadering voornamelijk het werven van nieuwe klanten centraal staat, ligt bij relatiemarketing de klemtoon op het opbouwen, uitdiepen en onderhouden van duurzame en hechte relaties (die meer dan één transactie omvatten) met bestaande klanten. Relatiemarketing richt zich dus op het versterken van klantenbinding, en het stimuleren van herhaald aankoopgedrag ten gevolge van expliciete voorkeuren (Dwyer, Schurr en Oh 1987).

De economische voordelen die resulteren uit het opbouwen van lange-termijnrelaties met klanten zijn omvangrijk en verklaren in veel bedrijfstakken een aanzienlijk deel van het verschil in winstgevendheid tussen bedrijven. Zo loonden Reichheld en Sasser (1990) alan dat ondernemingen hun winsten kunnen doen stijgen met bijna $100 \%$ door slechts $5 \%$ meer klanten te behouden, of door de gemiddelde levensduur van

Drs. I. Geyskens is als doctoraalstudent verbonden aan het Departement Toegepaste Economische Wetenschappen van de Katholieke Universiteit Leuven.

Prof. Dr. Ir. J.E.B.M. Steenkamp is gewoon hoogleraar aan het Departement Toegepaste Economische Wetenschappen van de Katholieke Universiteit Leuven en bijzonder hoogleraar aan de vakgroep Marktkunde van de Landbouwuniversiteit Wageningen. relaties met klanten te verdubbelen van 5 tot 10 jaar. Deze bevindingen werden recent bevestigd door Kalwani en Narayandas (1995). Uit hun studie blijkt dat bedrijven die lange-termijnrelaties met klanten uitbouwden lagere verkoop-en administratieve kosten hadden dan bedrijven die een transactiebenadering hanteerden, wat zich vertaalde in hogere winsten. Het werven van nieuwe klanten brengt namelijk gemiddeld vijf keer meer kosten met zich mee dan het behouden van bestaande klanten (Christopher, Payne en Ballantyne 1991).

Om de potentiële voordelen van lange-Iermijnrelaties te realiseren, is het creëren van een geest van vertrouwen ('trust') tussen de partijen in een relatie cruciaal (Anderson en Weitz 1989. Kumar 1996). Vertrouwen speelt namelijk een centrale rol in het opbouwen van tevredenheid en het oplossen van conflicten (Anderson en Narus 1990), en is één van de belangrijkste componenten van relatiekwaliteit (Kumar, Scheer en Steenkamp 1995a). Morgan en Hunt (1994) argumenteren dat vertrouwen essentieel is voor een succesvolle relatiemarketingstrategie. Dwyer, Schurr en Oh (1987) benadrukken dat vertrouwen prioritaire aandacht behoort te verkrijgen in onderzoek omtrent de totstandkoming van relaties, aangezien de graad van vertrouwen het al dan niet succesvol zijn van lange-termijnrelaties in belangrijke mate verklaart.

Zeker ook in de dienstensector kunnen vertrouwensvolle lange-termijnrelaties tussen de dienstverlener en de afnemer belangrijke voordelen opleveren. Het weinig grijpbare karakter van diensten leidt er immers toe dat de personen of instanties die de diensten verzorgen aan belang winnen (Crosby, Evans en Cowles 1990). Zo stelt KLM dat binding met reisagenten van levensbelang is. Eén van de strategische krachtlijnen van de Kredietbank, één 
van de grootste banken in België, bestaat uit het alangatan van duurzame, rendabele relaties met het cliënteel. Voor cen alintal diensten verwach de consument zelfs dat er een relatie zal opgebouwd worden (Jackson 1985). Zo zal de consument er bij de keuze van een bank doorgaans van uitgaan gedurende langere tijd met deze bank zaken te doen.

Gelet op hel belang van de diensiensector voor de economie en hel feil dat lange-termijnrelaties in deze sector zeer belangrijk zijn. is het verwonderlijk dat de literatuur omtrent relatiemarketing zich bijna uitsluitend geconcentreerd heeft op relaties tussen bedrijven ("business-10-business") in distributickanalen voor stoffelijke producten. Hierdoor blijft het belang van lange-termijnrelalies voor de dienstensector en de rol hiervan in het marketingbeleid onderbelicht. Hel doel van dit artikel is dan ook om cen overzicht le geven vall de recente on wikkelingen betreffende de rol van vertrouwen in het opbouwen en onderhouden van relaties tussen dienstverleners en consumenten. Hierbij staan de volgende vragen centraal:

- hoe draagt het vertrouwen van klanten in hun dienstverlener bij tot het opbouwen en onderhouden van lange-termijnrelaties?

- hoe kan een dienstverlener het vertrouwen van zijn klanten winnen?

- is het creëren van vertrouwen een betere manier voor een dienstverlener om klanten alan zich te binden dan het vergroten van de afhankelijkheidspositie van deze klanten?

Om deze drie vragen te kunnen beantwoorden maken we gebruik van algemene inzichten opgedian in de marketingliteraluur over afzetkinalen.

\section{Wat is vertrouwen?}

In zowel de marketing als de psychologische literatuur wordt vertrouwen doorgaans gedefinieerd als de overtuiging dat de partner ecrlijk on welwillend is (ci. Kumar. Scheer en Steenkamp 1995a.b, Larzelere en Huston 1980. Rempel. Holmes en Zanna 1985). Het eerste facet, vertrouwen in de eerlijkheid van de partner. kan worden gedefinieerd als de overtuiging dat de partner betrouwbaar is (Morgan en Hunt 1994), zich alan zijn woord houdı (Anderson en Narus 1990). beloften nakomt (Larzelere en Huston 1980). en de moed heeft om beperkingen toe te geven en slecht nieuws mee te delen (Swan. Trawick en Silva 1985). Een eerlijke partner verzwijgt of vervormt relevante informatie niet on eigen gezichtspunten kracht bij te zelten. maar zal er daarentegen over waken dal mesgedeelde feiten. ideeën en conclusies in hoge mate accuratat zijn en met de werkelijkheid overeenkomen (Moorman. Deshpandé en Zaltman 1993).

Hoewel eerlijkheid de eerste stap vormt naar vertrouwen. is het op zich niel voldoende om van vertrouwen te kunnen spreken. De klant moet er ook van overtuigd zijn dat de dienstverlener welwillend is. Dit tweede facel van vertrouwen vertrouwen in de welwillendheid van de partner kan gedelinieerd worden als de overtuiging dat de dienstverlener oprecht begalan is met het welzijn en de helangen van de klant, en geen onverwachte acties zal ondernemen zonder er rekening mee te houden hoe die de klant beïnvloeden (Anderson en Narus 1990. Kumar, Scheer en Steenkamp 1995a). Bovendien is een welwillende dienstverlener hulpvalardig, staat hij altijd klatar om bijstand te verlenen, en stelt lange-termijngroepsbelangen steeds boven zijn eigen korte-termijnbelangen (Crosby. Evans en Cowles 1990). Doorheen al deze delinities van welwillendheid loopt een rode dralid: de dienstverlener moel aan de klant een gevoel van zekerheid met betrekking tot de toekomst vin de relatie kunnen bieden.

Elk van de twee facelten. eerlijkheid en welwillendheid. is nodig om van vertrouwen te kunnen spreken (Kumar 1996). Eerlijkheid is het fundament van vertrouwen: zonder eerlijkheid kan vertrouwen niet groeien. Een klant riakt overtuigd van de eerlijkheid vall een diensiverlener op basis van zijn ervaringen met deze dienstverlener in het verleden (Larzelere en Husion 1980. Morgan en Hunt 1994). In een relatie is hel echter onmogelijk om op basis van het verleden de toekomst steeds exact te voorspellen, aangezien in de loop van de tijd omstandigheden kunnen wijzigen en onverwachte situaties kunnen opduiken (Rempel. Holmes en Zanna 1985). Daarom is welwillendheid, dat gericht is op de toekomst. een tweede noodzakelijk element in een delinitie van vertrouwen.

\section{De rol van vertrouwen bij het uitbouwen van lange-termijnrelaties}

Dat vertrouwen van strategisch belang is wordt door vele bedrijven onderschreven. In een onderzoek onder managers uit verschillende industrietakken werd gevraagd naar de belangrijkste karakieristieken die een goede klant van een gemiddelde klant onderscheiden. Van de 24 kenmerken kreeg het 
aanwezig zijn van vertrouwen in de relatie de Iweede hoogste prioriteit (Moody 1992). Zo stelt bijvoorbeeld de Kredietbank: "Wij willen onze klanten veel minder binden mel waarborgen maar meer mel service en vertrouwen " (Andriesse en Holzhauer 1994, p. 11 ).

Parallel met deze ontwikkeling in het bedrijisleven zien we dat in de marketingliteratuur het concept "vertrouwen" sterk in de belangstelling is komen te staan (zie onder andere Anderson en Weitz 1989, Anderson en Narus 1990, Ganesan 1994. Kumar 1996, Kumar, Scheer en Steenkamp 1995a.b. Moorman, Deshpandé en Zaltman 1993. Morgan en Hunt 1994). Dit onderzoek heefi reeds belangrijke inzichten opgeleverd omtrent de centrale plaats die vertrouwen inneemt bij het opbouwen van lange-termijnrelaties. Meer bepaald blijkt vertrouwen de effecten van belangrijke antecedenten (zoals bijvoorbeeld communicatic) op de lange-termijnoriëntatie van de relatiepartners te mediëren, zoals wordt weergegeven in liguur 1. Dit impliceert dat allerlei factoren die in het verleden werden aangehaald als zijnde belangrijk voor het opbouwen van lange-termijnrelaties grotendeels via vertrouwen hun invloed uitoefenen op het al dan niet slagen van lange-termijnrelaties. Een meta-analyse over alle beschikbare studies omtrent vertrouwen heen vond dat vertrouwen een mediërende (en dus ook centrale) rol uitoefent in een nomologisch net van antecedenten en gevolgen (Geyskens. Steenkamp en Kumar 1996).

Hoe draagt vertrouwen nu precies bij tot het ontwikkelen van lange-termijnrelaties? In eerste instantie laat vertrouwen de klant toe gevoelens van twijfel en onzekerheid te overwinnen ten aanzien van het maken van de juiste keuze van dienstverlener uit het spectrum van potentiële dienstverleners. Dit gevoel van zekerheid dal men mel de 'juiste' dienstverlener zaken doet, leidt ertoe dat klanten bereid zijn in de toekomst van de relatie te investeren: hun vrees geëxploiteerd te

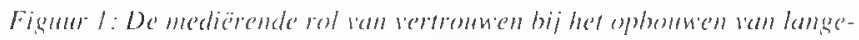
termijnrelaties $K=$ klamt: $D=$ dienstrerlener)

\section{D's opportunistisch}

gedrag

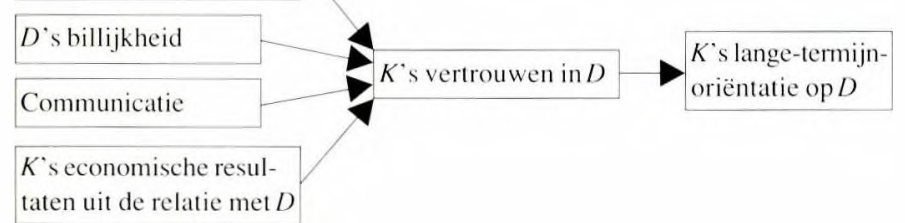

worden door de dienstverlener wordı immers gemitigeerd door het alanwezige vertrouwen (Ganesan 1994). Verder zorgt het grotere gevoel van zekerheid warartoe vertrouwen leidt ervoor dal een klant die problemen ervaart. deze op tafel gaat leggen in plaats van ze te verzwijgen (Anderson en Narus 1990). Hoewel dit tot conflicten kan leiden, zullen deze normaliter relatief constructief van aard zijn en doorgaans op vriendschappelijke voel worden opgelost, wat de productiviteit van de relatie enkel ten goede kan komen (Morgan en Hunt 1994). Dit alles verbetert de kwaliteit en de levensduur van de klant-dienstverlenerrelatie.

Ten Iweede ontstaat er door vertrouwen meer goodwill bij klanten ten aanzien van de dienstverlener. In elke relatic zal een partij wel eens een datad stellen die door de andere partij als destructief wordt ervaren. Zo kan. bijvoorbeeld, een bank hatar tarieven wijzigen in het nadeel van hat cliënten. Een vertrouwensvolle klant zal zich in zulke situaties toleranter opstellen en deze tariefaampassingen eerder toeschrijven aan een externe factor (zoals de sterk toegenomen kosten ) dan aan het overdreven winstbejag van de bank. Verder zal een vertrouwensvolle klant crvan overtuigd zijn dat zaken die in de korte termijn in zijn nadeel uitvallen. over de lange termijn zullen worden opgelost (Ganesan 1994. Morgan en Hunt 1994). Hogere goodwill helpt dus om de slechtere perioden in een relatie te overleven, en levert de organisatie 'krediet' op bij de klant (Achrol 1991). Als vertrouwen laag is, vind het omgekeerde proces plaats: problemen zullen juist negaliever worden gepercipieerd dan in werkelijkheid gerechtvalardigd is, waardoor de kwaliteit en de verwachte levensduur van de relatie er snel op achteruit gaan.

\section{Het creëren van vertrouwen in een relatie}

Gegeven dat vertrouwen zo belangrijk is voor het opbouwen en ontwikkelen van lange-termijnrelaties. is de cruciale vraag: hoe kan vertrouwen worden gecreëerd?

Met andere woorden, welke stappen kan een dienstverlener ondernemen om een goede vertrouwensrelatie met zijn klanten op te bouwen? In deze paragraaf geven wij een overzicht van de stand van zaken van het wetenschappelijk onderzoek rond hel creëren van vertrouwen. Het bespreken van alle antecedenten van vertrouwen die in de literatuur zijn onderzocht zou ons te ver leiden 
(zie Geyskens, Steenkamp en Kumar 1996 voor een overzicht). We beperken ons hier dan ook tot die antecedenten die een relatief sterk effect hebben op vertrouwen, die meer dan één maal werden bestudeerd en die vooral in een dienstencontext van belang kunnen zijn (zie ook figuur 1).'

\section{Opportunistisch gedrag}

Opportunistisch gedrag kan worden gedefinieerd als het nastreven van eigenbelang vanwege de dienstverlener door impliciete en expliciete beloften ten aanzien van de klant te verbreken (John 1984). Wanneer een klant gelooft dat de dienstverlener zich opportunistisch gedraagt, dan zal dit leiden tot een grote breuk in vertrouwen. Om een vertrouwensvolle relatie met klanten op te bouwen dient de dienstverlener er dus op te letten dat klanten niet de indruk krijgen dat ze worden bedrogen en geëxploiteerd. Hiertoe is het belangrijk dat de dienstverlener aangeeft dat het vertrouwen wederzijds is en niet enkel van de zijde van de klant komt (John 1984), bijvoorbeeld door de klant ervan te overtuigen dat hij niet enkel geïnteresseerd is in diens winstpotentieel, maar ook in diens persoon. Een gebruikelijke strategie is de klant als een individu in plaats van een nummer te behandelen, door de klant met zijn naam aan te spreken, door de tijd te nemen voor de klant, en door de klant geen bijkomende diensten te verkopen tenzij hij die echt nodig heeft. In totaal werd in twee studies het effect van opportunistisch gedrag op vertrouwen onderzocht: Dwyer en Oh (1987) en Morgan en Hunt (1994). De correlatie tussen vertrouwen en opportunisme was gemiddeld $-.647 .{ }^{2}$

\section{Billijkheid}

Recent onderzoek in de USA en Nederland (Kumar, Scheer en Steenkamp 1995a) heeft uitgewezen dat billijkheid ('fairness') een belangrijke rol speelt bij het opbouwen van vertrouwensvolle relaties. Er kan hier een onderscheid worden gemaakt tussen 'billijkheid van procedures' en 'billijkheid van resultaten'. Billijkheid van resultaten geeft de perceptie van de klant weer met betrekking tot de verdeling van inbreng in en resultaten uit de relatie. Een relatie is billijk in de ogen van de klant wanneer klant en dienstverlener in dezelfde mate in verhouding tot hun inbreng worden beloond. Een billijke relatie is een indicatie voor de klant dat beide partijen aandacht besteden aan dat ieder zijn 'deel' krijgt, wat tot hoger vertrouwen leidt. Een relatie wordt als onbillijk ervaren door de klant wanneer de klant zich ondergewaardeerd voelt ten opzichte van de dienstverlener. Ondergewaardeerde klanten hebben doorgaans het idee dat de dienstverlener kosten naar hen doorschuift. Ze beginnen hierdoor vijandige gevoelens tegenover de dienstverlener te koesteren, wat leidt tot minder vertrouwen.

Billijkheid van procedures omvat de billijkheid van het beleid dat de dienstverlener ten opzichte van de klant hanteert. Billijke procedures hebben volgende zes kenmerken: 1) bilaterale communicatie, 2) onpartijdigheid (alle klanten worden gelijk behandeld), 3) weerlegbaarheid (klanten kunnen de beslissingen van de dienstverlener in vraag stellen), 4) uitleg (de dienstverlener legt de klanten de redenen van zijn beslissingen uit), 5) deskundigheid (de dienstverlener kent en begrijpt de persoonlijke situatie van zijn klant), en 6) hoffelijkheid (de dienstverlener is beleefd en respectvol). Kumar, Scheer en Steenkamp (1995a) vonden dat billijkheid van procedures een groter effect heeft op het cultiveren van vertrouwen bij de klant dan billijkheid van resultaten ( $\mathrm{r}=.711$ versus $\overline{\mathrm{r}}=.432$ ). Een dienstverlener heeft immers zijn beleid en procedures altijd onder controle, terwijl het economisch rendement van de klant ook door zaken die niet onder de controle van de dienstverlener vallen kan beïnvloed worden (denk bijvoorbeeld aan de competitieve situatie). Billijkheid van procedures weerspiegelt met andere woorden beter de houding van de dienstverlener ten opzichte van zijn klanten.

\section{Communicatie}

Organisaties die expliciet streven naar het opbouwen van een vertrouwensvolle relatie met klanten dienen de dialoog met de klant aan te gaan. Het dient hier wel duidelijk om een tweerichtingscommunicatie te gaan, zoniet komt wantrouwen in plaats van vertrouwen tot stand. Vanuit de dienstverlener naar de klant toe dient productinformatie en persoonlijk advies te worden verstrekt. Het is belangrijk dat het hier gaat om op maat gesneden informatie, zodat de klant onmiddellijk begrijpt waar het om gaat en niet overspoeld wordt door irrelevante berichten. De dienstverlener moet echter ook de mogelijkheid creëren voor klanten om gemakkelijk in contact te treden met de dienstverlenende onderneming, bijvoorbeeld door het invoeren van hotlines. Zo is het belangrijk dat klanten ergens met hun vragen of klachten terechtkunnen. De mogelijkheid tot 
klagen biedt de dienstverlener de gelegenheid om corrigerend op te treden en zodoende het vertrouwen van de consument te versterken. Door enerzijds een scherper inzicht te bekomen in de behoeften en voorkeuren van klanten (via communicatie van klant naar dienstverlener), en anderzijds de verwachtingen van klanten beter in lijn te brengen met de realiteit (via communicatie van dienstverlener nalar klant) is de dienstverlener beter in staat aan de verwachtingen van zijn klanten te beantwoorden (Morgan en Hunt 1994). Dit bevestigt en versterkt het vertrouwen van klanten in hun dienstverlener. Empirisch onderzoek naar de sterkte van de relatie tussen vertrouwen en communicatie is uitgevoerd door Anderson, Lodish en Weilz (1987), Anderson en Weitz (1989), Anderson en Narus (1990) (voor een steekproef van distributeurs en een steekproef van producenten), Crosby, Evans en Cowles (1990), Morgan en Hun (1994) en Schurr en Ozanne (1985). De gemiddelde correlatie was $\vec{r}=.381$.

\section{Economische resultaten}

Ten slotte hebben ook de economische resultaten die een klant uit de relatie met zijn dienstverlener verkrijgt een belangrijke invloed op vertrouwen. Economische resultaten worden doorgaans gedefinieerd als de resultaten (zoals prijs, kwaliteit, service) die een klant bij de huidige dienstverlener verkrijgt. vergeleken met wal hij zou kunnen verkrijgen moest hij zaken doen met de beste alternatieve diensiverlener. In zes steekproeven. gerapporteerd in vier artikels, werden economische resultaten gerelateerd tot vertrouwen (Anderson en Narus 1990. Kumar. Scheer en Steenkamp 1995a. Morgan en Hunt 1994. Scheer en Stern 1992). De resultaten zijn opmerkelijk consistent: de gemiddelde correlatie tussen vertrouwen en economische resultaten bedroeg $\mathrm{r}=.430$.

\section{Vertrouwen ten opzichte van binding door afhankelijkheid}

Afhankelijkheid en macht zijn lange tijd centrale constructen geweest in onderzoek omtrent relaties in distributiekanalen (bijvoorbeeld Anderson en Narus 1990. Ganesan 1994, Kumar. Scheer en Steenkamp 1995b). Zo stelt, bijvoorbeeld Thorelli (1986. p. 38): 'Power is the central concept in network analysis because its mere existence can condition others'. Athankelijkheid wordt vaak gedefinieerd als de mate waarin het moeilijk is de huidige partner te vervangen (Kumar. Scheer en Steenkamp 1995b), waarbij verder wordt aangenomen dat A's afhankelijkheid van B overeenstemt met B's macht over A (Emerson 1962). Zo is een klant in hoge mate athankelijk van zijn huidige dienstverlener, wanneer de kosten om over te schakelen natar een andere dienstverlener hoog oplopen of wanneer er weinig alternatieve dienstverleners voor handen zijn waarmee hij zaken zou kunnen doen.

Recent hebben verscheidene onderzoekers geargumenteerd dat een volledig beeld van de structuur van een relatie zowel 'totale onderlinge afhankelijkheid' als 'afhankelijkheidsasymmetrie' dient te omvatten (Gundlach en Cadotte 1994. Kumar, Scheer en Steenkamp 1995b). Totale onderlinge alhankelijkheid geeft de som weer van $A$ 's athankelijkheid van $B$ en $B$ 's athankelijkheid van $A$. Afhankelijkheidsasymmetrie geeft het verschil weer tussen $A$ 's athankelijkheid van $B$ en $B$ 's athankelijkheid van A. Een relatie wordt symmetrisch genoemd indien $A$ en $B$ in dezelfde mate athankelijk van elkaar zijn. Een grotere totale afhankelijkheid zou het aangaan van langetermijnrelaties in positieve zin beïnvloeden. afhankelijkheidsasymmetrie daarentegen zou nefast zijn voor het bereiken van stabiele langetermijnrelaties.

Uit een sludie (Geyskens, Steenkamp, Scheer en Kumar 1996) waarin wij zowel vertrouwen als de athankelijkheidsstructuur van de relatie opnamen als mogelijke bindingsgronden voor relaties, blijkt dat de rol die afhankelijkheid speelt bij het opbouwen van lange-termijnrelaties veel kleiner is dan in het algemeen wordt aangenomen. Het al dan niet tot stand komen van lange-termijnrelaties werd bijna uitsluitend gedreven door de graad van vertrouwen die de relatie karakteriseert. We kunnen dan ook besluiten dat vertrouwen een sterkere bindingsgrond vormt dan athankelijkheid.

\section{Besluit}

In dit artikel hebben we een antal aspecten met betrekking tol vertrouwen tussen dienstverleners en consumenten behandeld. Er begint langzamerhand een consensus te ontstaan in de marketingliteratuur over de inhoud van het begrip vertrouwen. Vertrouwen is een subjectief begrip, waarbij percepties en overtuigingen centraal stilan. De dimensies van vertrouwen zijn eerlijkheid en welwillendheid. In een dienstencontext 
kunnen we het vertrouwen van een klant in een dienstverlener dan ook omschrijven als de overtuiging van de klant dat de dienstverlener zich aan zijn woord houdt en oprecht begaan is met het welzijn van de klant.

Klanten zijn sneller geneigd een lange-termijnrelatie op te bouwen met een dienstverlener die ze vertrouwen. Consumentenvertrouwen gaat immers gepaard met grotere gevoelens van zekerheid (ten aanzien van het gemaakt hebben van de juiste keuze van dienstverlener) en tolerantie (ten aanzien van occasionele, voor de klant destructieve daden gesteld door de dienstverlener) vanwege de consumenten.

Vertrouwen is echter meer dan zomaar een belangrijke variabele voor marketingrelaties. Vertrouwen neemt een centrale positie in bij het boeken van relatiemarketingsuccessen, hetgeen zich uit in de mediërende rol die vertrouwen uitoefent in een nomologisch net van antecedenten en gevolgen. Dit impliceert dat acties van dienstverleners grotendeels via vertrouwen hun invloed uitoefenen op het al dan niet slagen van langetermijnrelaties. Met andere woorden, wanneer dienstverleners acties plannen ter bevordering van de lange-termijnrelaties met hun klanten, zouden ze zich steeds behoren af te vragen of, en in welke mate, die acties het klantenvertrouwen beïnvloeden.

Op basis van voorgaand empirisch onderzoek kunnen we stellen dat acties die aan te raden zijn om consumentenvertrouwen te creëren, bestaan uit het regelmatig en voldoende diepgaand communiceren met klanten, en het opbouwen van een billijk beleid. Billijkheid van resultaten blijkt ook een versterkende invloed op vertrouwen uit te oefenen, doch in veel geringere mate dan billijkheid van procedures. Dienstverleners doen er dan ook verstandig aan om zich in eerste instantie te concentreren op de billijkheid van hun procedures, in plaats van op het verlagen van hun prijzen. Verder dient te allen tijde te worden voorkomen dat klanten het idee krijgen dat de dienstverleners hun macht misbruiken, om zo hun klanten te exploiteren en hieruit zelf zoveel mogelijk voordeel te putten.

Hoewel het belang van consumentenvertrouwen in het algemeen door vele dienstverleners wordt onderschreven, blijken pogingen om een hoger vertrouwen bij klanten te realiseren vaak te stranden en niet de beoogde resultaten te leveren. De oorzaken voor het falen van deze programma's berusten er vaak in dat alles 'bij woorden' blijft.
Vele dienstverleners schijnen onvoldoende te beseffen dat het spelen van de 'vertrouwenskaart' doorgaans vraagt om substantiële aanpassingen van hun werkklimaat, hun managementstijl en de houding en attitudes van de personen die hierbij betrokken zijn. Het doorvoeren van zulke aanpassingen vraagt veel tijd en energie, maar precies om deze redenen kan het opzetten van relaties waarin wantrouwen heeft plaatsgemaakt voor vertrouwen, en waarin de nadruk is verlegd van verkoopsuccesjes op korte termijn naar continuitteit van de relatie op langere termijn, leiden tot verdedigbare competitieve voordelen ten opzichte van de rivalen.

\section{I T E R A T U U R}

Achrol, R., (1991), Evolution of the marketing organization: new forms for turbulent environments, Journal of Marketing, 55 (October), pp. 77-93

Anderson, E., L.M. Lodish en B.A. Weitz, (1987), Resource allocation behavior in conventional channels, Journal of Marketing Research, 24 (February), pp. 85-97.

Anderson, E. en B. Weitz, (1989), Determinants of continuity in conventional industrial channel dyads, Marketing Science, 8 (Fall), pp. 310-323.

Anderson, J.C. en J.A. Narus, (1990), A model of distributor firm and manufacturer firm working partnerships, Journal of Marketing, 54 (January). pp. 42-58.

Andriesse, F.G. en F.F.O. Holzhauer, (1994), Kredietbank succesvol met retentiemarketing, Tiidschrift voor Marketing, Maart, pp. 9-12.

Berry, L.L., (1983), Relationship marketing, in: L.L. Berry, L. Shostack en G.D. Upah (eds.), Emerging perspectives on services marketing, American Marketing Association, Chicago, pp. 25-28.

Christopher, M., A. Payne en D. Ballantyne, (1991), Relationship marketing: Bringing quality, customer service, and marketing together, Butterworth-Heinemann Ltd, Oxford.

Crosby, L.A., K.R. Evans en D. Cowles, (1990), Relationship quality in services selling: an interpersonal influence perspective, Journal of Marketing, 54 (July), pp. 68-81.

Dwyer, F.R. en S. Oh, (1987), Output sector munificence effects on the internal political economy of marketing channels, Journal of Marketing Research, 24 (November), pp. 347-358.

Dwyer, F.R., P.H. Schurr en S. Oh, (1987), Developing buyerseller relationships, Journal of Marketing, 51 (April), pp. 11-27.

Emerson, R.M., (1962), Power-dependence relations, American Sociological Review, 27 (February), pp. 31-42. 
Ganesan, S., (1994), Determinants of long-term orientation in buyer-seller relationships, Journal of Marketing, 58 (April), pp. 1-19.

Geyskens, I., J.B.E.M. Steenkamp en N. Kumar, (1996), Generalizations about trust in marketing channel relationships using meta-analysis, Working paper.

Geyskens, I., J.B.E.M. Steenkamp, L.K. Scheer en N. Kumar, (1996), The effects of trust and interdependence on relationship commitment: A trans-Atlantic study, International Journal of Research in Marketing, 13 (4), pp. 303329.

Gundlach, G.T. en E.R. Cadotte, (1994), Interdependence and interfirm influence: results from a simulated channel setting, Journal of Marketing Research, 31 (November), pp. 516-532.

Jackson, B.B., (1985), Winning and keeping industrial customers: The dynamics of customer relationships, Lexington Books, Lexington

John, G., (1984), An empirical investigation of some antecedents of opportunism in a marketing channel, Journal of Marketing Research, 21 (August), pp. 278-289.

Kalwani, M.U. en N. Narayandas, (1995), Long-term manufacturer-supplier relationships: do they pay off for supplier firms?, Journal of Marketing, 59 (January), pp. 1-16.

Kumar, N., (1996), The power of trust in manufacturer-retailer relationships, Harvard Business Review, NovemberDecember, 92-106.

Kumar, N., L.K. Scheer en J.B.E.M. Steenkamp, (1995a), The effects of supplier fairness on vulnerable resellers, Journal of Marketing Research, 32 (February), pp. 54-65.

Kumar, N., L.K. Scheer en J.B.E.M. Steenkamp, (1995b), The effects of perceived interdependence on dealer attitudes, Journal of Marketing Research, 32 (August), pp. 348-356.

Larzelere, R.E. en T.L. Huston, (1980), The dyadic trust scale: toward understanding interpersonal trust in close relationships, Journal of Marriage and the Family, 42 (August), pp. 595-604.

Moody, Patricia E., (1992), Customer supplier integration: why being an excellent customer counts, Business Horizons, July-August, pp. 52-57

Moorman, C., G. Deshpande en R. Zaltman, (1993), Factors affecting trust in market research relationships, Journal of Marketing, 57 (January), pp. 81-101.
Morgan, R.M. en S.D. Hunt, (1994), The commitment-trust theory of relationship marketing, Journal of Marketing Research, 58 (July), pp. 20-38.

Reichheld, F.F. en W.E. Sasser, (1990), Zero defections: quality comes to services, Harvard Business Review, 68 (September-October), pp. 105-111.

Rempel, J.K., J.G. Holmes en M.P. Zanna, (1985), Trust in close relationships, Journal of Personality and Social Psychology, 49 (1), pp. 95-112.

Scheer, L.K. en L.W. Stern, (1992), The effect of influence type and performance outcomes on attitude toward the influencer, Journal of Marketing Research, 29 (February), pp. 128-142.

Schurr, P.H. en J.L. Ozanne, (1985), Influences on exchange processes: buyers' preconceptions of a seller's trustworthiness and bargaining toughness, Journal of Consumer Research, 11 (March), pp. 939-953.

Swan, I., F. Trawick en D. Silva, (1985), How industrial salespeople gain customer trust: A conceptual guide for the salesperson, Industrial Marketing Management, 14 (August), pp. 203-211.

Thorelli, H.B., (1986), Networks: between markets and hierarchies, Strategic Management Journal, 7, pp. 37-51.

\section{NOTEN}

1 De tijdschriften die werden geraadpleegd zijn: AMA Proceedings, International Journal of Research in Marketing, Journal of Business Research, Journal of Consumer Research, Journal of Marketing, Journal of Marketing Research, Journal of Retailing, Marketing Letters en Marketing Science, voor de periode van 1970 tot en met 1995.

2 De gewogen gemiddelde correlatie $\bar{r}$ werd berekend volgens de formule: $\Sigma n_{i} r / \Sigma n$. In deze formule stelt $r$ de correlatie voor tussen vertrouwen en het betreffende antecedent zoals die werd gerapporteerd in studie $i$, en $n$, het aantal observaties in studie i. Door te wegen, wordt een groter gewicht toegekend aan correlaties die gebaseerd zijn op grotere steekproeven. 